\title{
Localization of Heparin-binding EGF-like Growth Factor in the Smooth Muscle Cells and Macrophages of Human Atherosclerotic Plaques
}

\author{
Jun-ichiro Miyagawa, " Shigeki Higashiyama," Sumio Kawata, * Yoshiaki Inui, * Shinji Tamura, * Koji Yamamoto, * \\ Makoto Nishida, * Tadashi Nakamura, * Shizuya Yamashita, * Yuji Matsuzawa, * and Naoyuki Taniguchi" \\ *The Second Department of Internal Medicine and ${ }^{\ddagger}$ Department of Biochemistry, Osaka University Medical School, \\ Yamadaoka, 565 Japan
}

\begin{abstract}
Heparin-binding EGF-like growth factor (HB-EGF) is a potent chemoattractant and mitogen for smooth muscle cells (SMC) in culture. To elucidate whether HB-EGF is implicated in the pathogenesis of human atherosclerosis, we examined immunohistochemical localization of HB-EGF in human aortic walls and atherosclerotic plaques. The medial SMC of the aorta in babies and children synthesized HBEGF protein, while the number of SMC producing HBEGF was dramatically decreased in young and middle-aged adults. In atherosclerotic plaques, however, marked production of HB-EGF protein was detected in SMC and macrophages of the plaques. Furthermore, EGF receptors, to which HB-EGF is known to bind, were detected in plaque SMC. These data suggest that HB-EGF may be implicated in the migration and proliferation of SMC that occurs in the normal development of arterial walls, and in the formation of atherosclerotic plaques. (J. Clin. Invest. 1995. 95:404-411.) Key words: HB-EGF • atherosclerosis • macrophages - SMC • EGF receptor
\end{abstract}

\section{Introduction}

The process of atherogenesis in the arterial wall is characterized by the formation of fibrous fatty lesions that are a result of inflammatory processes such as the infiltration of monocytederived macrophages and $\mathrm{T}$ lymphocytes, and the proliferation of neointimal smooth muscle cells (SMC) ${ }^{1}$ which have migrated in from the media (1). It has been suggested that cells

\footnotetext{
J.-i. Miyagawa and S. Higashiyama contributed equally to this work. Address correspondence to Dr. Shigeki Higashiyama, Department of Biochemistry, Osaka University Medical School, 2-2, Yamadoaka, Suita, 565 Japan. Phone: 6-879-3421; FAX: 6-879-3429; or Dr. Yuji Matsuzawa, The second Department of Internal Medicine, Osaka University Medical School, 2-2, Yamadaoka, Suita, Osaka, 565 Japan. Phone: 6-879-3732; FAX: 6-879-3739.

Received for publication 14 December 1993 and in revised form 10 April 1994.
}

1. Abbreviations used in this paper: $\mathrm{ABC}$, avidin-biotin complex; $\mathrm{bFGF}$, basic fibroblast growth factor; EGFR, EGF receptor; HB-EGF, heparinbinding EGF-like growth factor; SMC, smooth muscle cells.

J. Clin. Invest.

(C) The American Society for Clinical Investigation, Inc.

0021-9738/95/01/0404/08 $\$ 2.00$

Volume 95, January 1995, 404-411 in the atherosclerotic lesion such as endothelial cells, macrophages, SMC, and T lymphocytes produce growth factors that are involved in the progression of the lesions of atherosclerosis to a fibrous plaque or an advanced, complicated lesion (2). One growth factor that in particular is implicated in atherogenesis is PDGF, a potent chemoattractant for monocytes and SMC as well as a potent SMC mitogen (3). It has been suggested that PDGF released from degranulated platelets during thrombosis is responsible for stimulating SMC migration into the intima and for subsequent SMC proliferation (3). However, the source of PDGF could also be macrophages, endothelial cells, and SMC all of which synthesize this growth factor $(3,4)$. In situ hybridization of PDGF A and B chain mRNAs in mesenchymal cell-like cells of atherosclerotic plaques (5) and immunohistochemistry of PDGF B chain protein in the atherosclerotic lesion (6) indicate a significant role of PDGF in the process of atherogenesis.

Another possible growth factor that could be involved in atherogenesis is basic fibroblast growth factor (bFGF), a potent mitogen for SMC produced by endothelial cells, SMC, and macrophages (7). It has been suggested that bFGF is in part responsible for intimal cell proliferation associated with atherosclerotic lesions since it is a potent stimulator of SMC proliferation and has been implicated in the proliferation of SMC and intimal thickening after balloon catheter injury of rat carotid artery (8).

Furthermore it has been shown that the cell types associated with atherosclerotic lesion synthesize other SMC growth regulators besides PDGF and bFGF, including IGF-1 (9), TGF- $\beta$ $(10-15)$, IL-1 $(16,17)$, and TNF- $\alpha(18)$.

Heparin-binding EGF-like growth factor (HB-EGF) is a newly discovered potent SMC mitogen and chemoattractant which was originally identified in human macrophage-conditioned medium $(19,20)$. HB-EGF is a member of the EGF family and is synthesized as a transmembrane precursor (proHB-EGF), a characteristic of members of the EGF family proteins, which is processed to the mature 86-amino acid form of HB-EGF. The mature HB-EGF which spans residues 63148 of proHB-EGF has two characteristic domains; a highly hydrophilic domain with an affinity for heparin in the $\mathbf{N H}_{2-}$ terminal region and an EGF-like domain with 35\% homology to human EGF in the $\mathrm{COOH}$-terminal region (20-22). HBEGF has been shown to interact with the same high affinity receptors as EGF on human fetal SMC (23) and bovine aortic SMC (24). A heparin-binding domain of HB-EGF spanning residues 93-113 of proHB-EGF has been shown to interact with heparan sulfate proteoglycans on the surfaces of bovine aortic SMC and to modulate binding to EGF receptor (24). It has been suggested that the heparin-binding property of $\mathrm{HB}$ - 
EGF, which is lacking in EGF, may be responsible for its greatly enhanced migration activity (33-fold) and mitogenic activity (40-fold) for bovine aortic SMC as compared with EGF (20, 24). HB-EGF is comparable with PDGF in that it is synthesized by macrophages and SMC, and is also a potent mitogen and chemoattractant for SMC $(20,24)$. These properties of HBEGF prompted us to investigate whether it was associated with the pathogenesis of atherosclerosis.

\section{Methods}

Tissue materials. Thoracic and abdominal aortae were obtained from 31 individuals at autopsy aged $2 \mathrm{mo}-80 \mathrm{yr}$, some of which had atherosclerosis.

Preparation of antibodies against proHB-EGF. Antibodies recognizing mature and proHB-EGF were produced by immunizing female white New Zealand rabbits with a synthetic peptide H-1 (HB-EGF precursor COOH-terminal residues 185-208) and H-6 (HB-EGF precursor residues 54-73). A cysteine residue was introduced in each peptide at its $\mathrm{COOH}$-terminal site and conjugated to ovalbumin (Sigma Chemical Co., St. Louis, MO) by sulfosuccinimidyl 6-(3-[2-pyridyldithio]propionamido)hexanoate (sulfo-LC-SPDP) (Pierce, Rockford, IL) according to a manufacturer manual. The protein was emulsified with complete Freund adjuvant (Difco Laboratories Inc., Detroit, MI) before injection into the rabbits. Neither antibody H-1 nor H-6 has amino acid sequence homology with other members of the EGF family proteins such as EGF, TGF- $\alpha$ and amphiregulin (25). H-1 does not cross react with mature HB-EGF purified from U-937 cell-conditioned medium by Western blotting and immunoprecipitates ${ }^{35}$ S-labeled proHB-EGF. H-6 cross reacts with purified U-937-derived mature HB-EGF (21). Neither antibody detected EGF, TGF- $\alpha$, or amphiregulin by Western blotting (Higashiyama, S., and N. Taniguchi, manuscript submitted for publication). In this study, we used both $\mathrm{H}-1$ and $\mathrm{H}-6$ antibodies.

Immunohistostaining. For immunohistochemical detection of HBEGF, tissues from aortic walls obtained at autopsy within $5 \mathrm{~h}$ of death were fixed with $5 \%$ phosphate-buffered formalin for $5 \mathrm{~h}$ at $4^{\circ} \mathrm{C}$. After a wash in PBS, the tissues were decalcified in decalcifying solution B (Wako Pure Chemical Industries, Ltd., Osaka, Japan) for $3 \mathrm{~d}$ at $4^{\circ} \mathrm{C}$. Paraffin sections $(\sim 4 \mu \mathrm{m})$ were deparaffinized, treated with $3 \% \mathrm{H}_{2} \mathrm{O}_{2}$ solution for $10 \mathrm{~min}$, and were washed in distilled water for $5 \mathrm{~min}$ and

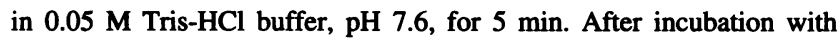
normal swine serum for 20 min at room temperature, a three-step immunoperoxidase method was performed using a rabbit anti-HB-EGF antiserum (H-1 or H-6) diluted $1 / 200$ in Tris buffer containing $1 \%$ BSA (for $30 \mathrm{~min}$ at room temperature), swine anti-rabbit immunoglobulins (DAKO, Glostrup, Denmark) diluted 1/200 in Tris buffer containing $1 \% \mathrm{BSA}$ (for $20 \mathrm{~min}$ at room temperature), and peroxidase-labeled, rabbit anti-peroxidase immunoglobulins (PAP) complexes (for $20 \mathrm{~min}$, at room temperature). The tissue sections were visualized with 3-amino9-ethylcarbazol (AEC) (both from DAKO) in $0.1 \mathrm{M}$ acetate buffer, $\mathrm{pH}$ 5.2 , in the presence of $0.3 \% \mathrm{H}_{2} \mathrm{O}_{2}$ : As a negative control, the primary antiserum (H-1 or H-6) was replaced by normal rabbit serum (DAKO), or preabsorbed with excess amount of the peptide antigen. For detection of EGF-receptors (EGFR), tissue sections were incubated in $0.1 \% \mathrm{H}_{2} \mathrm{O}_{2}$ in methanol for $10 \mathrm{~min}$, washed in PBS for $20 \mathrm{~min}$ and then incubated in $0.05 \%$ saponin (Wako Pure Chemical Industries, Ltd.) in distilled water for $30 \mathrm{~min}$ at room temperature. To detect the localization of EGFR, the avidin-biotin complex (ABC) method of OSI immunohistochemistry was used. Sections were incubated with $0.5 \%$ normal goat serum for $20 \mathrm{~min}$ at room temperature, and then with rabbit anti-human EGFR polyclonal antibody raised against the peptide which corresponds to $1005-1016$ residues of EGFR diluted $1 / 20$ in PBS containing $1 \%$ BSA for $60 \mathrm{~min}$ at room temperature. After a wash in PBS, sections were incubated with biotinylated goat anti-rabbit IgG diluted 1/200 in PBS containing $1 \% \mathrm{BSA}$, and OSI@ ABC reagent (all from Oncogene Science, Inc., Manhasset, NY) for $30 \mathrm{~min}$ at room temperature. The tissue sections were visualized by incubation in peroxidase substrate solution containing DAB (3,3'-diaminobenzidine)/nickel chloride
Table I. Clinical Status or Cause of Death in Subjects With or Without Atherosclerosis

\begin{tabular}{|c|c|c|c|}
\hline $\begin{array}{l}\text { Case } \\
\text { No. }\end{array}$ & Age, sex & Clinical status or cause of death & $\begin{array}{l}\text { Atherosclerosis } \\
\text { (plaque formation) }\end{array}$ \\
\hline 1 & $2 \mathrm{mo}, \mathrm{F}$ & Herniation of diaphragm & - \\
\hline 2 & $4 \mathrm{mo}, \mathrm{F}$ & Intestinal intussusception & - \\
\hline 3 & $6 \mathrm{mo}, \mathrm{F}$ & Down syndrome, cardiac anomaly & - \\
\hline 4 & $10, \mathbf{M}$ & Leukemia & - \\
\hline 5 & $10, F$ & Trauma & - \\
\hline 6 & $24, M$ & Trauma & - \\
\hline 7 & $33, \mathrm{M}$ & Leukemia & - \\
\hline 8 & $38, \mathrm{M}$ & Hypertrophic cardiomyopathy & - \\
\hline 9 & $42, M$ & Aplastic anemia & - \\
\hline 10 & $44, M$ & $\begin{array}{l}\text { Sudden death (clinical status; } \\
\text { unknown) }\end{array}$ & - \\
\hline 11 & $48, M$ & Gastric cancer & - \\
\hline 12 & $52, \mathrm{~F}$ & Colon cancer & - \\
\hline 13 & $53, \mathrm{M}$ & Trauma & - \\
\hline 14 & $54, \mathrm{M}$ & Rectal cancer, diabetes mellitus & + \\
\hline 15 & $55, \mathrm{M}$ & Esophageal cancer & - \\
\hline 16 & $55, \mathrm{M}$ & $\begin{array}{l}\text { Hepatocellular carcinoma, liver } \\
\text { cirrhosis }\end{array}$ & - \\
\hline 17 & $56, \mathrm{M}$ & Hepatocellular carcinoma & - \\
\hline 18 & $60, F$ & Trauma & + \\
\hline 19 & $60, M$ & Esophageal cancer & - \\
\hline 20 & $60, M$ & Pancreas cancer & - \\
\hline 21 & $62, M$ & $\begin{array}{l}\text { Angina pectoris, cardiac and renal } \\
\text { failure }\end{array}$ & + \\
\hline 22 & $66, F$ & Diabetes mellitus, renal failure & + \\
\hline 23 & $68, M$ & Gastric cancer & - \\
\hline 24 & $71, \mathbf{M}$ & Myocardial infarction & + \\
\hline 25 & $72, \mathrm{M}$ & Pancreas cancer & - \\
\hline 26 & $75, \mathrm{M}$ & Myocardial infarction, hypertension & + \\
\hline 27 & $75, \mathbf{M}$ & Cerebellar infarction & + \\
\hline 28 & $75, M$ & Cardiac tamponade, hypertension & + \\
\hline 29 & $78, \mathrm{M}$ & Prostate cancer & + \\
\hline 30 & $76, \mathrm{M}$ & Multiple cerebral infarction & + \\
\hline 31 & $80, \mathbf{M}$ & Colon cancer & + \\
\hline
\end{tabular}

M, male, F, female. The presence or absence of atherosclerosis was examined in the thoracic and abdominal aorta.

(Zymed Labs, Inc., San Francisco, CA) for 10-20 min at room temperature.

Identification of cell types. To identify macrophages and SMC in atherosclerotic aorta, deparaffinized tissue sections were incubated with $0.3 \% \mathrm{H}_{2} \mathrm{O}_{2}$ in methanol, washed in PBS for $20 \mathrm{~min}$, and incubated with $0.1 \%$ trypsin in PBS for $30 \mathrm{~min}$ at room temperature. Sections were then incubated with $1.5 \%$ normal horse serum for $20 \mathrm{~min}$ at room temperature, and incubated with a mouse monoclonal antibody against human macrophages (CD-68, KP1; DAKO) diluted 1/200 in PBS containing $0.5 \%$ BSA, or a mouse monoclonal antibody against an $\alpha$ isoform of SMC actin (histofine; Nichirei Co. Ltd., Tokyo, Japan). After washing in PBS, the ABC method was used to detect macrophages and SMC using biotinylated horse anti-mouse IgG diluted 1/2,000 in PBS for $30 \mathrm{~min}$ at room temperature and vecstatin ${ }^{8} \mathrm{ABC}$ reagent (both from Vector Labs Inc., Burlingame, CA) for $30 \mathrm{~min}$ at room temperature. Positive reaction was visualized as described in the method for detecting EGFR.

\section{Results}

Clinical status. Clinical status or cause of death of each individual was listed in Table I. None of them died from any severe 

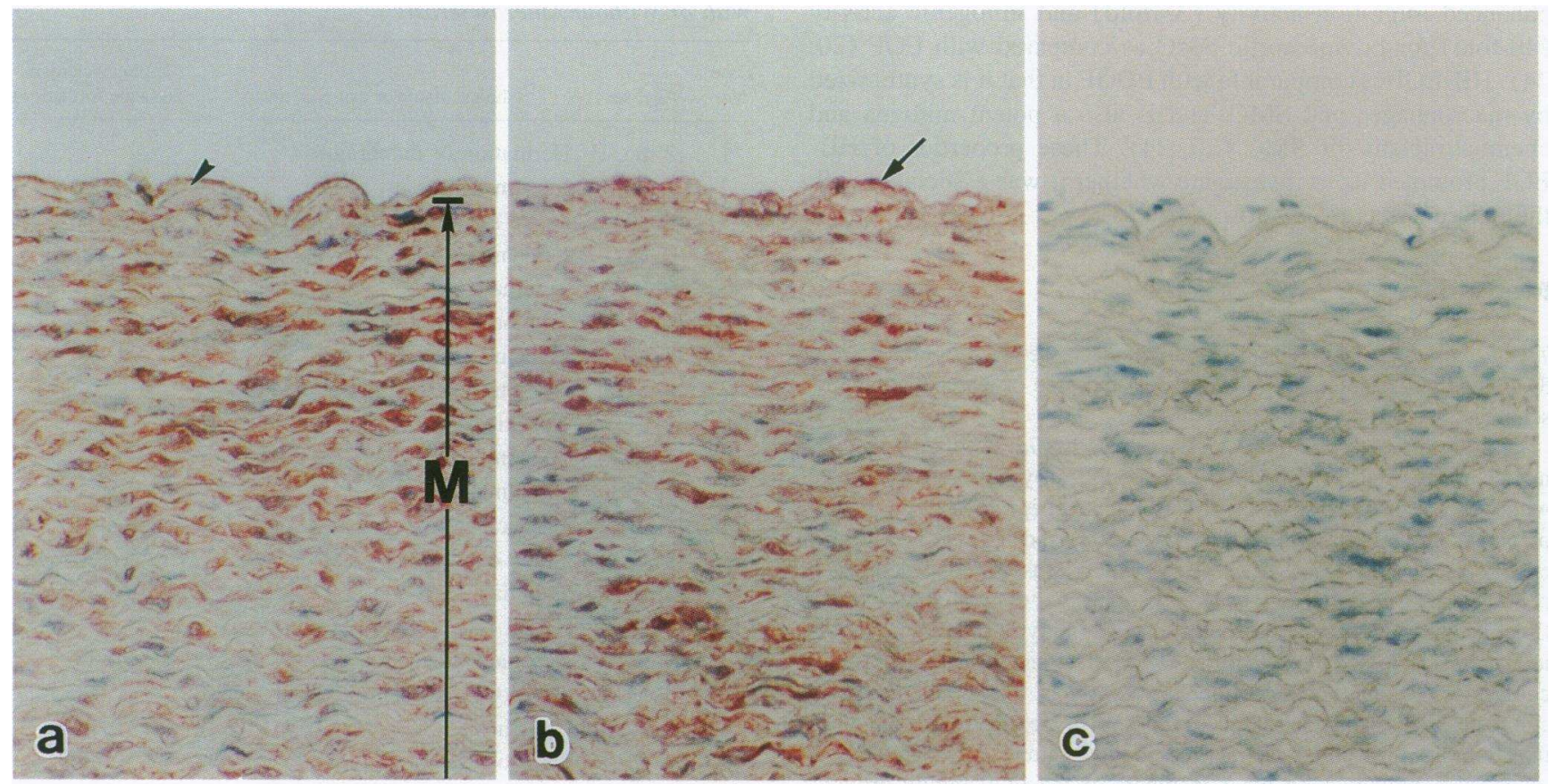

Figure 1.
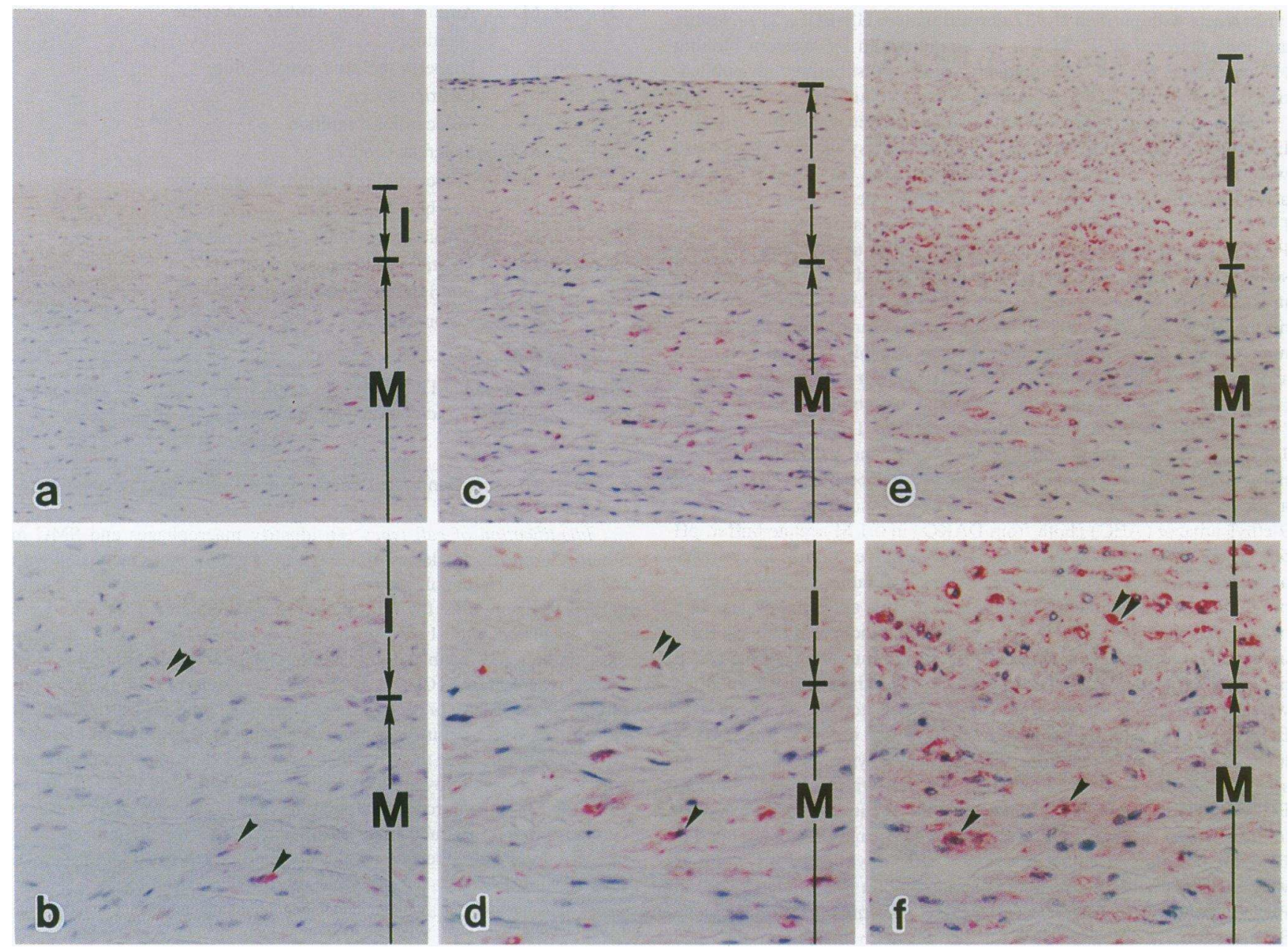

Figure 2. 
infectious disease which might induce or alter the production of HB-EGF protein in SMC of aortic wall. When thoracic and abdominal aorta were opened up, the entire portion was examined grossly. Presence or absence of atherosclerosis was determined by whether typical atherosclerotic lesions such as fibrous plaque, fibro-fatty plaque, and advanced lesion with occasional calcification were observed. When the vessel examined was atherosclerotic, at least five different tissues of the plaque lesions $\left(\sim 4 \mathrm{~cm}^{2}\right)$ and three tissues of nonatherosclerotic portion $\left(\sim 4 \mathrm{~cm}^{2}\right)$ were excised from different areas.

Immunohistochemical detection of $H B-E G F$ in arterial walls without atherosclerotic plaques. In a 4-mo-old baby, intense immunostaining of HB-EGF was detected in medial SMC and endothelial cells of the aorta. Intima consisted of endothelial cell layer and thin connective tissue space where cell infiltrate was rarely observed. Both antibodies $\mathrm{H}-1$ and $\mathrm{H}-6$, which recognize cytoplasmic domain (proform of HB-EGF) and extracellular domain (proform and mature form of HB-EGF), respectively, demonstrated almost the same staining pattern (Fig. 1, $a$ and $b$ ). The positive immunohistochemical staining was completely abrogated when these antibodies were preabsorbed by excess amounts of each antigen peptide (Fig. $1 c$ ). On the other hand, in the aortic wall of a 24-yr-old adult showing mild intimal thickening, the number of medial SMC immunostained positively for HB-EGF was markedly decreased (Fig. 2, $a$ and $b$ ). The number of medial SMC producing HB-EGF tended to increase gradually in parallel with the increase of age. In a 60 yr-old adult without atherosclerosis, we could recognize that SMC positively stained for HB-EGF in the media especially of intimal side were increased in number (Fig. 2, $c$ and $d$ ). However, HB-EGF-positive SMC in the media appeared to be substantially increased in the aorta of individuals with atherosclerosis compared with young and middle-aged adults without atherosclerosis (Fig. 2, $e$ and $f$ ). The number of medial SMC positively stained for HB-EGF was analyzed quantitatively in 31 individuals and summarized in Fig. 3. The percentage of HB-EGF-positive cells in medial SMC was greatly elevated in groups of babies and young children ( 2 mo-10 yr) compared with young and middle-aged adults. In the adult group (26 individuals), the relationships between the presence or absence

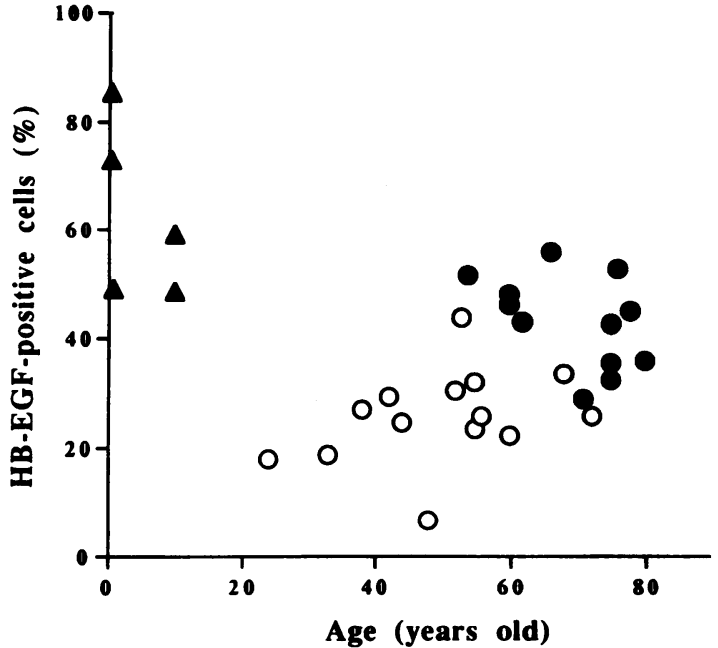

Figure 3. Percentage of HB-EGF-positive cells in the medial SMC in 31 subjects of various age. Each point express the percentage of HBEGF-positive SMC in babies and children ( 4 ) $(2$ mo-10 yr $)$, adults without atherosclerotic plaques $(0)(24-72 \mathrm{yr})$ and adults with atherosclerotic plaques $(\bullet)(54-80 \mathrm{yr})$. Immunostaining for HB-EGF was carried out using antibody $\mathrm{H}-1$, and followed by counter-staining for the nucleus with Mayer's hematoxylin. The number of nuclei of HBEGF-positive SMC which showed positive red or red-brown immunohistochemical reaction in the cytoplasm and total SMC were counted using a tablet measure unit for micromeasurement (krypton-40; Flovel, Tokyo, Japan $)$ in the intimal side area of medial walls $\left(0.5 \mathrm{~mm}^{2}\right)$. Each point is the average of three different areas.

of atherosclerosis and the percentage of HB-EGF-positive cells or aging were examined by a multiple regression analysis. The multiple correlation coefficient was 0.802 , indicating that both parameters, the percentage of HB-EGF-positive cells and aging, are related to the presence of atherosclerosis by positive regression coefficient respectively, and are statistically significant $(P=0.0016$ and $P=0.0117$, respectively $)$.

Immunohistochemical detection of HB-EGF in atherosclerotic plaques. Thickness of the intima in aortic wall was gradu-

Figure 1. HB-EGF localization in a baby aorta. The thoracic aorta of a 4-mo-old baby (case No. 2) was immunostained for HB-EGF using two kinds of polyclonal antibodies H-1 $(a)$ and H-6 $(b)$, which recognize cytoplasmic domain of proHB-EGF and extracellular domain of mature and proHB-EGF, respectively. ( $a$ and $b$ ) The intima consists of an endothelial cell lining which is continuous to the internal elastic lamina ( $a$, arrowhead). Almost all the SMC in the media of the aortic wall showed intense staining of HB-EGF (red-brown color). The staining pattern and the localizationof HB-EGF-positive cells by $\mathrm{H}-1$ and $\mathrm{H}-6$ antibodies were essentially the same, although slightly intense staining could be obtained by antibody H1. Endothelial cells were also immunostained positively for HB-EGF $(b$, arrow $)$. $(c)$ Immunostaining was completely abolished by incubation of anti-HB-EGF H-6 serum preincubated with the synthetic peptide antigen. Both anti-HB-EGF H-1 serum preincubated with the synthetic peptide antigen and normal rabbit serum also showed the same results (data not shown). $M$, media. Counter-staining for the nucleus (blue color) was carried out by Mayer's hematoxylin. $(a, b$, and $c$ : original magnification $\times 250)$.

Figure 2. Localization of HB-EGF in adult aortae with and without atherosclerosis. Immunostaining for HB-EGF was carried out by H-6 antibody. $(a$ and $b$ ) In the aorta of a 24-yr-old male (case No. 6) without atherosclerosis, medial SMC with positive immunostaining for HB-EGF ( $b$, arrowhead) were markedly decreased in number compared with baby aorta shown in Fig. 1. Intima showed mild thickening and some of the intimal cells were HB-EGF-positive ( $b$, double arrowhead). $(c$ and $d)$ Normal aorta without any atherosclerotic lesion from a 60-yr-old male (case No. 19 ) showed diffusely thickened intima. Medial SMC with positive immunostaining for HB-EGF ( $d$, arrowhead) were slightly increased in number compared with young adult shown in Fig. 2, $a$ and $b$. Small round HB-EGF-positive cells in the subendothelial region, and HB-EGF-positive cells of various shape just above the media ( $d$, double arrowhead) were recognized. ( $e$ and $f$ ) In the aorta of a 60 -yr-old male with atherosclerosis (case No. 21), medial SMC with positive HB-EGF staining ( $f$, arrowhead) were further increased even in a region of diffusely thickened intima (not a region of plaque formation) in the aorta with atherosclerotic plaque compared with those in normal aorta of the same age in $c$ and $d$. Intimal cells were markedly increased in number, and numerous cells showed intense immunostaining for HB-EGF ( $f$, double arrowhead). $I$, intima; $M$, media. Counter-staining for the nucleus (blue color) was carried out by Mayer's hematoxylin. $(a, c$, and $e$ : original magnification $\times 90$. $b, d$ and $f$ : original magnification $\times 180$ ). 

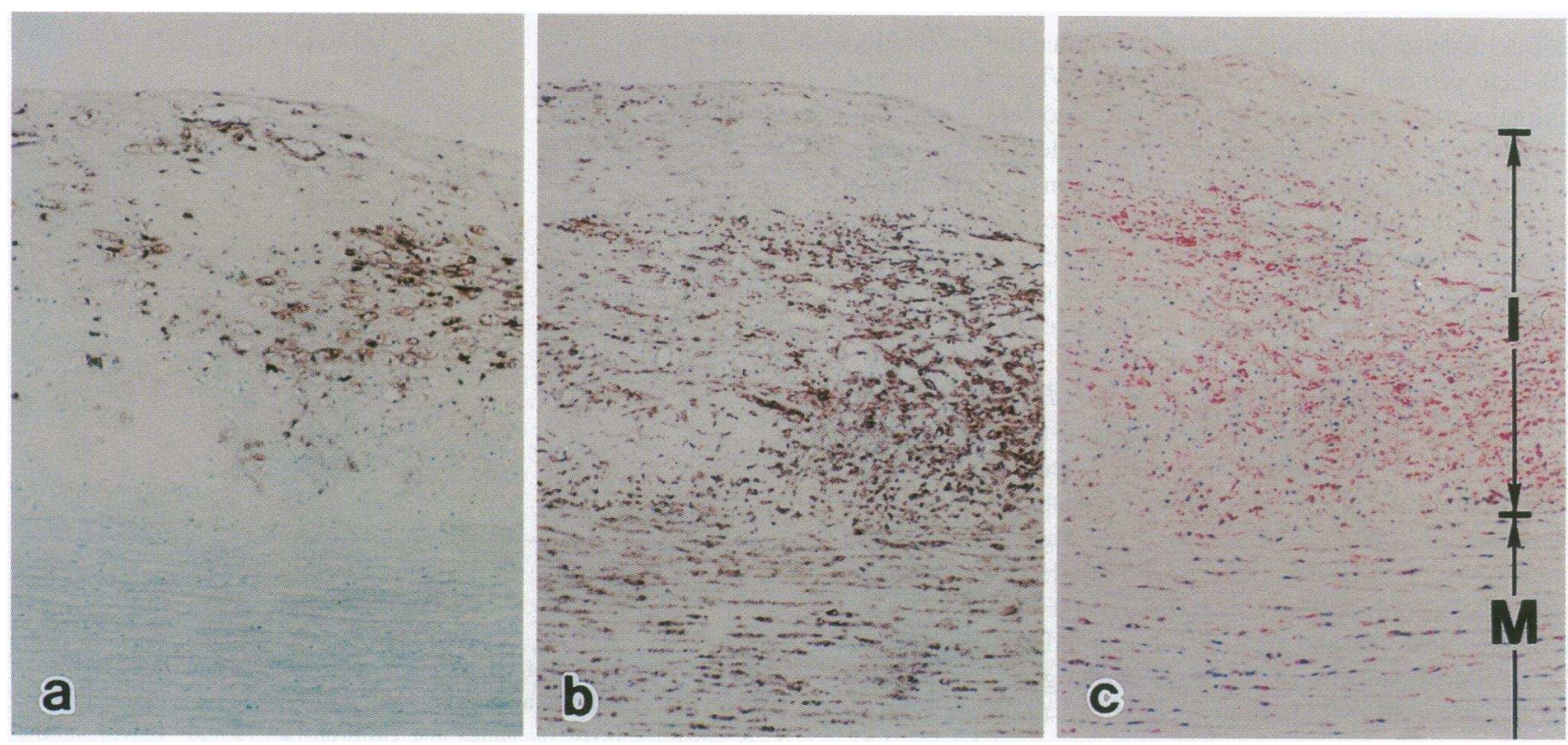

\section{Figure 4.}
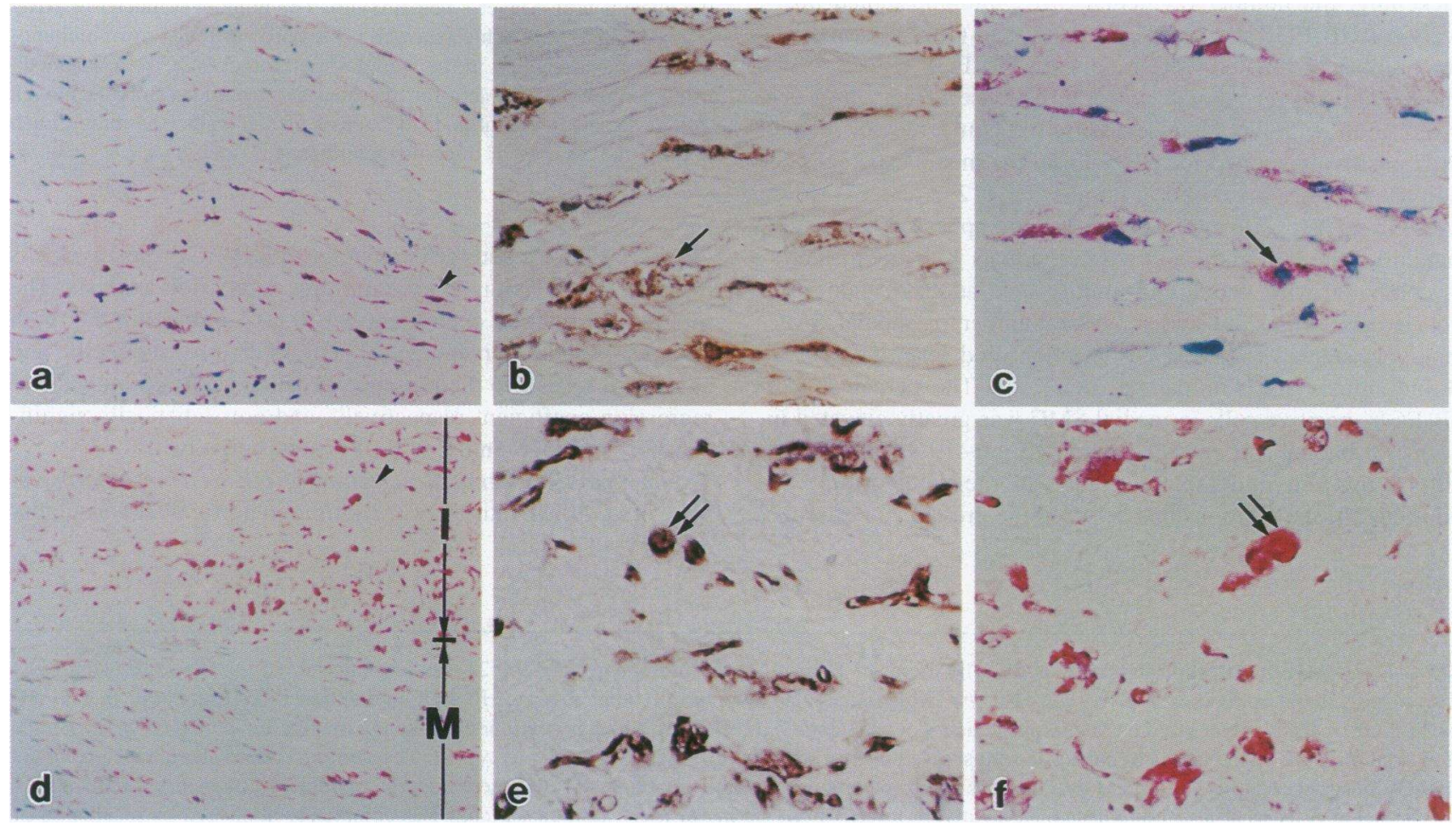

\section{Figure 5.}

Figure 4. Localization of macrophages, SMC, and HB-EGF-positive cells in aorta with an atherosclerotic plaque. Macrophages (a), SMC (b), and HB-EGF $(c)$ stainings were carried out in the aorta with atherosclerotic plaque from a 60-yr-old female (case No. 18). (a) Macrophages were recognized accumulating into the plaque. (b) In addition to medial SMC, numerous cells with positive immunostaining for $\alpha$-smooth muscle cell actin were observed in the plaque. (c) Many of the cells in the plaque were positive for HB-EGF protein detected by anti-HB-EGF H-6 antibody, and both macrophages and SMC appeared to be HB-EGF positive, although some foam cells rich in lipid materials showed vacuolated cytoplasm and were faintly stained by the antibody. $I$, intima; $M$, media. Counter-staining for the nucleus in $(a)$ and $(b)$, and $(c)$ was carried out by methyl green and Mayer's hematoxylin, respectively. $(a, b$, and $c$ : original magnification $\times 35)$.

Figure 5. HB-EGF protein localization in two types of cells in atherosclerotic plaques. Atherosclerotic plaques of an 80-yr-old female (case No. 31) $(a, b$, and $c)$ and a 60-yr-old female (case No. 18) $(d, e$, and $f)$ were analyzed for HB-EGF $(a, c, d$, and $f)$, macrophages $(b)$ and SMC $(e)$ immunostaining. (a) Positive immunostaining for HB-EGF using anti-HB-EGF H-1 antibody was observed in many cells in the central part of atherosclerotic plaque. These cells showed various shapes and sizes, and appear to be heterogeneous in cell population (original magnification 
ally increased with the increase of age ("physiological" intimal thickening), that appeared to be the result of the accumulation of both extracellular matrices and intimal cells derived from circulating blood mononuclear cells and medial SMC (Fig. 2) (2). In atherosclerotic plaques, however, numerous cells including foam cells could be observed, and the number of intimal cells was much larger than that of normal aorta (Figs. 2 and 4). Immunohistochemical staining for macrophage and SMC demonstrated that both cell types were the major cell constituent in the atherosclerotic plaque (Fig. 4, $a$ and $b$ ). HB-EGF staining in the consecutive section revealed that numerous cells were strongly positive for HB-EGF protein (Fig. $4 c$ ). These cells appeared to be macrophages and SMC from the results of macrophage- and SMC-specific staining, although lipid-laden foam cells were sometimes faintly recognized by anti-HB-EGF antibodies due to loss of the major part of the cytoplasm that is composed of lipid accompanied by the antigen during the processing of tissue samples. From the results of the staining pattern, at least two types of cells stained positively for HB-EGF were observed. One was a small cell of various shapes with intense and homogeneous staining of cytoplasm, the other a relatively large round-shaped or fibroblast-like cell with a fine granular staining pattern. However, it was difficult to determine the cell types from the difference in these staining patterns with low power magnification. We analyzed cell types in plaques positively stained for HB-EGF by the staining of mirror image sections with high power magnification.

Identification of cell types in plaques. To identify HB-EGFpositive cells in the plaque, sections were stained with monoclonal antibodies against macrophage- and SMC-specific antigens. Macrophages in the plaque were both round-shaped cells located closely to a cluster of foam cells as well as spindleshaped cells located around the lipid core region especially of the luminal side (Fig. 5, $a$ and $c$ ). In a set of mirror image sections (Fig. 5, $b$ and $c$ ), most of the cells that stained positively for macrophages (Fig. $5 \mathrm{~b}$ ) also stained positively for HB-EGF (Fig. 5 c). Many of the SMC also had a spindle shape, but were smaller in size than macrophages or foam cells. Round and plump SMC were often recognized in the region just above the media (Fig. 5, $d$ and $f$ ). In a set of mirror image sections (Fig. 5, $e$ and $f$ ), the SMC of the plaques were immunostained positively for the SMC (Fig. $5 e$ ) and HB-EGF protein (Fig. 5 $f$ ) located in this region showed the most intense staining for this protein. Taken together, these results revealed that at least two types of cells, one a macrophage and the other a SMC, could be potential sources of HB-EGF protein synthesis in atherosclerotic legions.

Immunohistochemical detection of EGF receptor (EGFR) in atherosclerotic plaques and aortic medial SMC. Since our previous studies have shown that cultured human fetal vascular SMC (23) and bovine aortic SMC (24) expressed EGFR and that the biological activity of HB-EGF for cultured SMC was mediated through the EGFR signaling pathway (24), EGFR availability in the aorta was evaluated. In atherosclerotic individuals, SMC in the intima were positive for EGFR staining, especially in the area just above the media. Furthermore, EGFR was detected in atherosclerotic plaque SMC and in medial SMC (Fig. $6 a$ ). However, in some atherosclerotic individuals, EGFR was stained faintly (Fig. $6 b$ ) or even negative in the medial SMC in our immunohistochemical studies. These results are consistent with HB-EGF synthesized in plaque macrophages being able to interact with EGFR on SMC in a paracrine manner, and/or SMC stimulating themselves in an autocrine manner. In nonatherosclerotic individuals, however, the detection level of EGFR in both intimal and medial SMC was extremely low (Fig. $6 d$ ).

\section{Discussion}

This study clearly demonstrated that HB-EGF, one of the growth factors of the EGF family, is expressed in SMC and macrophages in human aortic walls. Based on immunostaining results showing that HB-EGF levels of 12 individuals with various stages of atherosclerosis were higher than in normal adults, we speculate that HB-EGF might be continuously produced by sources such as SMC and macrophages, and stimulate SMC proliferation by autocrine and paracrine mechanisms. We also propose that HB-EGF synthesized by SMC and macrophages may be associated with the pathogenesis of atherosclerosis, especially with neointimal SMC migration, proliferation, and accumulation in the lesions of atherosclerosis. Within the EGF family, this activity may be specific for HB-EGF since it has been reported that gene expression level of TGF- $\alpha$ in the plaques of atherosclerosis is undetectable (5) and our immunohistochemical examination done in parallel with this study did not show positive TGF- $\alpha$ staining in any cells of the aortic wall (data not shown), and so far, no involvement of other members of the EGF family with atherosclerosis has been reported.

It is not known which regulatory factors are capable of inducing the expression of the HB-EGF gene in atherogenesis. Lysophosphatidylcholine (26), a major component of oxidized LDL (oxLDL), and thrombin (27) have been demonstrated to increase HB-EGF mRNA level and protein production in cultured macrophages and SMC, respectively. It has been suggested that oxLDL is a highly potent trigger of atherogenesis and may cause endothelial injury resulting in the formation of thrombin (28). Thus induction of HB-EGF by these factors is consistent with a role of this growth factor in atherogenesis. Since it has been reported that PDGF, bFGF, and HB-EGF itself upregulates HB-EGF gene expression in cultured SMC (29), the release of numerous growth-regulatory molecules and cytokines from a network established between cells recruited into the lesion may enhance HB-EGF production leading to activation, proliferation, and migration of SMC. It would be interesting to know how much expression of HB-EGF occurs in the hypertensive state of SMC since angiotensin II has been reported to upregulate HB-EGF gene expression in rat SMC (30).

\footnotetext{
$\times 120)$. ( $b$ and $c$ ) A set of paired mirror image sections showed the immunostaining of macrophages $(b)$ and HB-EGF (c). These are consecutive to the section showing a low power view in $a$, and the region where these high power views are from is indicated by an arrow in $a$. The same macrophage is pointed out by an arrow in $b$ and $c . b$ and $c$ : original magnification $\times 400$. (d) Numerous number of HB-EGF-positive cells could be also recognized in the region just above the media. Many of these cells showed intense immunostaining for HB-EGF protein. $I$, intima; $M$, media. (original magnification $\times 120$ ). ( $e$ and $f$ ) A set of paired mirror image sections showed the immunostaining of SMC $(e)$ and HB-EGF $(f)$. The same SMC is pointed out by a double arrow in $e$ and $f$. These sections are from the medial side of the plaque indicated by an arrow in $d$. $e$ and $f$ : original magnification $\times 400$.
} 

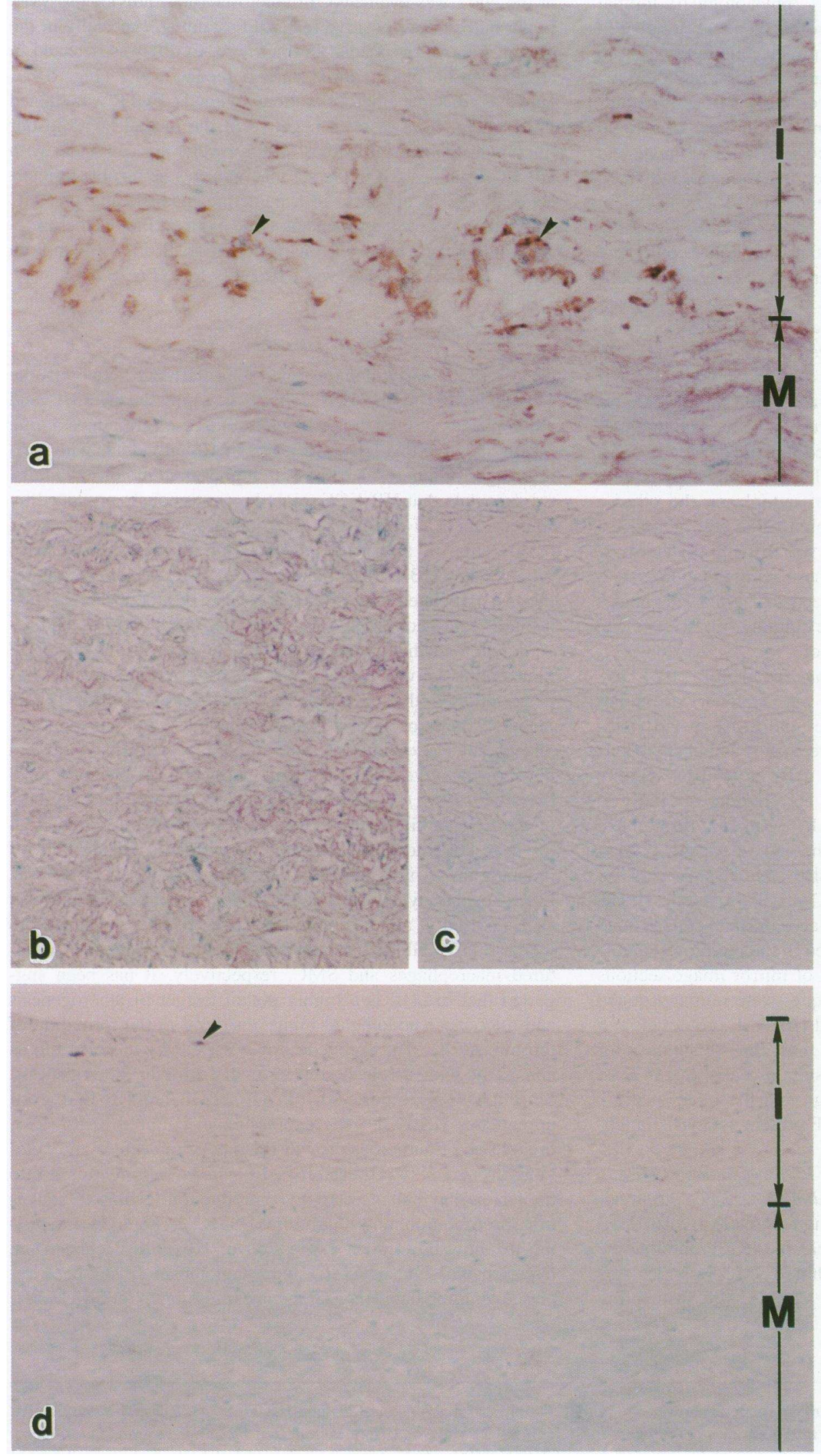

Figure 6. Expression of EGFR in atherosclerotic plaques. Immunostaining of EGFR was carried out on the neointimal SMC in the plaque from a 71-yr-old male (case No. 24) ( $a$ ) and in the medial wall under the plaque from a 60 -yr-old female (case No. 18) (b). (a) Neointimal SMC of various shapes (arrowhead) especially in the medial side region of the plaque showed more intense staining compared to medial SMC. I, intima; $M$, media. ( $b$ ) Slightly disarranged medial SMC showed faint immunostaining for EGFR. Staining intensity was different from case to case, and was negative in some cases. (c) Negative control for the section " $b$ " using normal rabbit serum instead of anti-EGFR antibody. (d) In the normal aortic wall, medial SMC positively stained for EGFR were rarely seen, although EGFR appeared to be expressed in some intimal cells ( $a r$ rowhead). I, intima; $M$, media. Counterstaining for the nucleus (light green) was carried out by methyl green. $(a, b$, and $c$ : original magnification $\times 250, d$ : original magnification $\times 180$ ). 
HB-EGF could be involved in SMC migration and proliferation not only in the process of atherogenesis but also in the normal development of aortic walls, since HB-EGF synthesis is high in the arterial walls of the neonate compared with the adult.

In contrast, HB-EGF needs to bind EGFR expressed on target cells to induce various biological events. In the aortic wall of atherosclerotic individuals, EGFR were expressed strongly in intimal SMC as compared with the extremely low level of EGFR staining in normal adult aortae. It is of interest that the intimal SMC of atherosclerotic individuals consistently expressed EGFR, while the medial SMC did not always express this receptor at least from the results of immunohistochemical analyses. To elucidate the pathogenesis of atherosclerosis, it seems to be important to know the regulatory mechanism of the expression of EGFR in SMC of the arterial wall as well.

Studies on the regulatory mechanism of HB-EGF gene expression and protein production might result in the formulation of HB-EGF inhibitory strategies useful for preventing the development of atherosclerosis. Possible anti-HB-EGF strategies include neutralizing antibodies and antisense oligonucleotides. Antibodies have been used to block PDGF and bFGF in a balloon injury model (31-33). An antisense to $c-m y b$ has a similar activity (34). Thus, it may be feasible to block HBEGF as well.

\section{Acknowledgments}

We are grateful to Dr. Michael Klagsbrun (Department of Surgery, Children's Hospital, Harvard Medical School) for helpful discussion and assistance in preparing the manuscript. We thank Mrs. K. Yamamori for technical assistance.

This work was supported in part by a Grant-in-Aid for Cancer Research for S. Higashiyama and N. Taniguchi (grant 05151047) and a Grant-in-Aid for Y. Matsuzawa (grant 04404085) from the Ministry of Education, Science, and Culture of Japan. S. Higashiyama is the recipient of a Searl Scientific Research Fellowship.

\section{References}

1. Ross, R. 1986. The pathogenesis of atherosclerosis. N. Engl. J. Med. 314:488-500.

2. Ross, R. 1993. The pathogenesis of atherosclerosis. Nature (Lond.) 362:801-809.

3. Ross, R., E. W. Raines, and D. F. Bowen-Pope. 1986. The biology of platelet-derived growth factor. Cell. 46:155-169.

4. Barrett, T. B., and E. P. Benditt. 1988. Platelet-derived growth factor gene expression in human atherosclerotic plaques and normal artery wall. Proc. Natl. Acad. Sci. USA 85:2810-2814.

5. Wilcox, J. N., K. M. Smith, L. T. Williams, S. M. Schwartz, and D. Gordon 1988. Platelet-derived growth factor mRNA detection in human atherosclerotic plaques by in situ hybridization. J. Clin. Invest. 82:1134-1143.

6. Ross, R., J. Masuda, E. W. Raines, A. M. Gown, S. Katsuda, M. Sasahara L. T. Malden, H. Masuko, and H. Saito. 1990. Localization of PDGF-B protein in macrophages in all phases of atherosclerosis. Science (Wash. DC). 248:10091012.

7. Klagsbrun, M., and E. R. Edelman. 1989. Biological and biochemica properties of fibroblast growth factors. Arteriosclerosis. 9:269-278.

8. Lindner, V., D. A. Lappi, A. Baird, R. A. Majack, and M. A. Reidy. 1991 Role of basic fibroblast growth factor in vascular lesion formation. Circ. Res. 68:106-113.

9. Banskota, N. K., R. Taub, K. Zellner, and G. L. King. 1989. Insulin, insulin like growth factor I and platelet-derived growth factor interact additively in the induction of the protooncogene $c-m y c$ and cellular proliferation in cultured bovine aortic smooth muscle cells. Mol. Endocrinol. 3:1183-1190.

10. Sporn, M. B., A. B. Roberts, L. M. Wakefield, and B. Crombrugghe.
1987. Some recent advances in the chemistry and biology of transforming growth factor-beta. J. Cell Biol. 105:1039-1045.

11. Roberts, A. B., and M. B. Sporn. 1990. The transforming growth factor$\beta$ s. In. Handbook of Experimental Pharmacology: Peptide Growth Facters and Their Receptors I. M. B. Sporn and A. B. Roberts, editors. Springer Verlag, Berlin. 419-472.

12. Moses, H. L., E. Y. Yang, and J. A. Pietenpol. 1990. TGF- $\beta$ stimulation and inhibition of cell proliferation. Cell. 63:245-247.

13. McCaffery, T. A., D. J. Falcone, C. F. Brayton, L. A. Agarwal, F. G. P. Welt, and B. B. Weksler. 1989. Transforming growth factor- $\beta$ activity is potentiated by heparin via dissociation of the transforming growth factor- $\beta / \alpha_{2}$-macroglobulin inactive complex. J. Cell Biol. 109:441-448.

14. Chaudhury, A. R., and P. A. D'Amore. 1991. Endothelial cell regulation by transforming growth factor-beta. J. Cell. Biochem. 47:224-229.

15. Battegay, E. J., E. J. Reines, R. A. Seifert, D. F. Bowen-Pope, and R. Ross. 1990. TGF- $\beta$ induces bimodal proliferation of connective tissue cells via complex control of an autocrine PDGF loop. Cell. 63:515-524.

16. Libby, P., G. B. Friedman, and R. N. Salomon. 1989. Cytokines as modulators of cell proliferation in fibrotic diseases. Am. Rev. Resp. Dis. 140:1114-1117.

17. Raines, E. W., S. K. Dower, and R. Ross. 1989. Interleukin-1 mitogenic activity for fibroblasts and smooth muscle cells is due to PDGF-AA. Science (Wash. DC). 243:393-346.

18. Old, L. J. 1985. Tumor necrosis factor (TNF). Science (Wash. DC) 230:630-632.

19. Besner, G. E., S. Higashiyama, and M. Klagsbrun. 1990. Isolation and characterization of a macrophage-derived heparin-binding growth factor. Cell Regul. 1:811-819.

20. Higashiyama, S., J. A. Abraham, J. Miller, J. C. Fiddes, and M. Klagsbrun. 1991. A heparin-binding growth factor secreted by macrophage-like cells that is related to EGF. Science (Wash. DC). 251:936-939.

21. Higashiyama, S., K. Lau, G. E. Besner, J. A. Abraham, and M. Klagsbrun. 1992. Structure of heparin-binding EGF-like growth factor. J. Biol. Chem. 267:6205-6212.

22. Thompson, S. T., S. Higashiyama, K. Wood, S. Pollitt, D. Damm, G. McEnroe, B. Garrick, N. Ashton, K. Lau, N. Hancock et al. 1994. Characterization of sequences within heparin-binding EGF-like growth factor that mediate interaction with heparin. J. Biol. Chem. 269:2541-2549.

23. Higashiyama, S., J. A. Abraham, D. Damm, and M. Klagsbrun. 1994 Heparin-binding EGF-like growth factor (HB-EGF) synthesis by smooth muscle cells. Horm. Res. (Basel). 42:9-13.

24. Higashiyama, S., J. A. Abraham, and M. Klagsbrun. 1993. Heparin-binding EGF-like growth factor stimulation of smooth muscle cell migration: dependence on interactions with cell surface heparan sulfate. J. Cell Biol. 122:933-940.

25. Plowman, G. D., J. M. Green, V. L. McDonald, M. G. Neubauer, C. M Disteche, G. J. Todaro, and M. Shoyab. 1990. The amphiregulin gene encodes a novel epidermal growth factor-related protein with tumor-inhibitory activity. Mol. Cell. Biol. 10:1969-1981.

26. Nakano, T., E. W. Raines, J. A. Abraham, M. Klagsbrun, and R. Ross. 1994. Lysophosphatidilcholine upregulates the level of heparin-binding EGF-like growth factor mRNA in human monocytes. Proc. Natl. Acad. Sci. USA 91:10691073.

27. Nakano, T., E. W. Raines, J. A. Abraham, F. G. Wenzel, IV, S. Higashiyama, M. Klagsbrun, and R. Ross. 1993. Glucocorticoid inhibits thrombin-induced expression of platelet-derived growth factor A-chain and heparin-binding epidermal growth factor-like growth factor in human aortic smooth muscle cells. $J$. Biol. Chem. 268:22941-22947.

28. Steinberg, D., S. Parthasarathy, T. E. Carew, J. C. Khoo, and J. L. Witztum. 1989. Modification of low-density lipoprotein that increase its atherogenecity. $N$. Engl. J. Med. 320:915-924.

29. Dluz, S. M., S. Higashiyama, D. Damm, J. A. Abraham, and M. Klagsbrun 1993. Heparin-binding epidermal growth factor-like growth factor expression in cultured fetal human vascular smooth muscle cells. J. Biol. Chem. 268:1833018334.

30. Temizer, D. H., M. Yoshizumi, M. A. Perrella, E. E. Susanni, T. Quertermous, and M.-E. Lee. 1992. Induction of heparin-binding epidermal growth factorlike growth factor mRNA by phorbol ester and angiotensin II in rat aortic smooth muscle cells. J. Biol. Chem. 267:24892-24896.

31. Ferns, G. A. A., E. W. Raines, K. H. Sprugel, A. S. Motani, M. A. Reidy, and R. Ross. 1991. Inhibition of neointimal smooth muscle accumulation after angioplasty by an antibody to PDGF. Science (Wash. DC). 253:1129-1132.

32. Lindner, V., and M. A. Reidy. 1991. Proliferation of smooth muscle cells after vascular injury is inhibited by an antibody against basic fibroblast growth factor. Proc. Natl. Acad. Sci. USA. 88:3739-3743.

33. Olson, N. E., S. Cho, V. Lindner, and M. A. Reidy. 1992. Intimal smooth muscle cell proliferation after balloon catheter injury. Am. J. Pathol. 140:10171023.

34. Simons, M., E. R. Edelman, J. C. DeKeyser, R. Langer, and R. D. Rosenberg. 1992. Antisense $c$ - $m y b$ oligonucleotides inhibit intimal arterial smooth muscle cell accumulation in vivo. Nature (Lond.). 359:67-70. 